\title{
SPED - SISTEMA PÚBLICO DE ESCRITURAÇÃO DIGITAL: PERCEPÇÃO DOS CONTRIBUINTES EM RELAÇÃO OS IMPACTOS DE SUA ADOÇÃO
}

PSDB - PUBLIC SYSTEM OF DIGITAL BOOKKEEPING: PERCEPTION FROM THE TAXPAYERS IN RELATION TO THE IMPACTS FROM ITS ADOPTION

\section{SPED - SISTEMA PÚBLICO DE ESCRITURACIÓN DIGITAL: PERCEPCIÓN DE LOS CONTRIBUYENTES EN RELACIÓN A LOS IMPACTOS DE SU ADOPCIÓN}

\section{CECÍLIA MORAES SANTOSTASO GERON}

Mestre em Controladoria e Contabilidade pela FEA-USP. Professora de Graduação na FECAP e Pós-Graduação Lato Sensu na Universidade Municipal de São Caetano do Sul

$(S P)$. Consultora de Empresas.

cecilia.geron@cjcontrole.com.br

\section{JOÃO RICARDO FINATELLI}

Especialista nas áreas de Controladoria e Gestão Tributária. Consultor de Empresas.

joao.finatell@aspr.com.br

\section{ANA CRISTINA DE FARIA}

Doutora e Mestre em Controladoria e Contabilidade pela FEA-USP. Professora no PósGraduação Stricto Sensu em Administração e Coordenadora dos MBAs em Controladoria e Gestão Tributária na Universidade Municipal de São Caetano do Sul (SP).

anacfaria@uol.com.br

\section{MARIA DO CARMO ROMEIRO}

Doutora e Mestre em Administração pela FEA-USP. Professora no Pós-Graduação Stricto Sensu em Administração e Diretora de Pesquisa Acadêmica e Aplicada na Universidade Municipal de São Caetano do Sul (SP). 


\section{repc}

\section{RESUMO}

O Governo brasileiro inspirou-se em modelos de Governos Eletrônicos de países como Espanha, Chile e México, entre outros, para a criação do Sistema Público de Escrituração Digital (SPED), entrando na era digital. A pesquisa exploratória desenvolvida neste trabalho tem como objetivo verificar se houve nas empresas melhorias operacionais quando da adoção do SPED. Essas melhorias, tais como a redução de tempo na emissão de NF, diminuição de erros, maior agilidade e produtividade nos processos de recebimento e de transporte de mercadorias, além de diminuição nos gastos com papel e armazenagem de documentos e diminuição das obrigações acessórias são apontadas pelas autoridades governamentais como fatores positivos para as empresas. No tratamento dos dados, empregou-se a Estatística Bivariada - com medidas de associação entre duas variáveis nominais -, Coeficiente Phi e V de Cramer. Os resultados obtidos foram comparados a estudo semelhante efetuado no Chile e verificou-se que os contribuintes brasileiros têm perspectivas diversas dos chilenos. Os respondentes não obtiveram resultados satisfatórios em termos de redução no tempo de emissão de uma nota fiscal, agilidade e produtividade no recebimento de mercadorias ou redução na aquisição de papel. Muitos têm a perspectiva de que terão benefícios no futuro, principalmente em relação à diminuição dos riscos de fraudes e dos custos operacionais.

Palavras-chave: Governo Eletrônico; Percepção; Sistema Público de Escrituração Digital - SPED.

\section{ABSTRACT}

The Brazilian Government used as a model the Electronic Governments of countries such as Spain, Chile and Mexico, among others, for creating the PSDB - Public System of Digital Bookkeeping, entering into the digital era. The exploratory research developed in this paper has the objective of verifying whether there has been operational improvements in the corporations as a result of the adoption of PSDB. These improvements, such as the time reduction for the issuance of $B S$, reduction of errors, greater flexibility and productivity in the process of goods reception and transport, in addition to the reduction in spending on paper and document storage and reduction of accessory obligations are pointed by government authorities as positive factors for corporations. When handling data, the Bivaried Statistics was utilized - using measures of association between two nominal variables - Phi Coefficient and Cramer V. The results obtained were compared to a similar study performed in Chile, and it was verified that the Brazilian taxpayers have perspectives different from Chileans'. The respondents have not obtained satisfactory results in terms of time reduction for issuing bills of sale, more agility and productivity in receiving goods or reduction in paper acquisition. 


\section{repec}

SPED - Sistema Público de Escrituração Digital: percepção dos contribuintes em relação os impactos de sua adoção

Many of them expect future benefits, mainly regarding the reduction in the risks of frauds and in the operational costs.

Key-words: Electronic Government; Perception; Public System of Digital Bookkeeping - PSDB.

\section{RESUMEN}

El Gobierno Brasileño se ha inspirado en modelos de Gobiernos Electrónicos de países como España, Chile y México, entre otros, para la creación del SPED - Sistema Público de Escrituración Digital, entrando en la edad digital. La investigación exploratoria desarrollada en este trabajo tiene como objetivo verificar si ha habido en las empresas mejoras operacionales a partir de la adopción del SPED. Esas mejoras, tales como la reducción del tiempo en la emisión de NF (factura), disminución de errores, mayor agilidad y productividad en los procesos de recibimiento y de transporte de mercaderías, más allá de la disminución en los gastos con papel y almacenamiento de documentos y disminución de las obligaciones accesorias son apuntadas por las autoridades gubernamentales como factores positivos para las empresas. En el trato de los datos se ha empleado la Estadística Bivariada - con medidas de asociación entre dos variables nominales - Coeficiente Phi y V de Cramer. Los resultados obtenidos han sido comparados a un estudio semejante llevado a cabo en Chile, y se ha verificado que los contribuyentes brasileños poseen perspectivas distintas a las de los chilenos. Los encuestados no han obtenido resultados satisfactorios en términos de reducción en el tiempo de emisión de una factura, agilidad y productividad en el recibimiento de mercaderías o reducción en la adquisición de papel. Muchos poseen la perspectiva de que tendrán beneficios en el futuro, principalmente en relación a la disminución de los riesgos de fraudes y de los costos operacionales.

Palabras clave: Gobierno Electrónico; Percepción; Sistema Público de Escrituración Digital - SPED.

\section{INTRODUÇÃO}

Hoje, no Brasil, a tributação representa um custo elevado de produção em relação ao Produto Interno Bruto (PIB). A variedade dos ramos de atividade das empresas existentes no País faz com que haja mais de 170 obrigações acessórias para serem cumpridas complementares à tributação (BRITTO, 2008, p. 1). Há uma deficiência específica de arrecadação, a qual se denomina sonegação (ou evasão fiscal). Em termos econômicos, o Governo não pode observar o valor real da base tributária do contribuinte e, com isso, a sua verdadeira responsabilidade tributária (SIQUEIRA, 2005, p. 557). Diante deste cenário, o 


\section{repc}

Governo reage e busca combater essa sonegação fiscal, controlando, cada vez mais, seu sistema de administração tributária.

Os avanços apresentados nas áreas da tecnologia da informação e comunicação eletrônica, tendo a internet como importante fator, interligam o mundo, garantindo a expansão da economia para mercados antigamente restritos. Essas novas tecnologias passaram a colaborar com os Governos no exercício de suas funções. De acordo com Helbig, Gil-García e Ferro (2005), o Governo Eletrônico envolve, basicamente, três tipos de transações: G2G, quando se trata de uma relação intra ou intergovernos; G2B, caracterizado por transações entre Governos e fornecedores ou pessoas jurídicas; e G2C, envolvendo relações entre Governos e cidadãos. Na opinião de Schedler e Scharf (2001), seja qual for o tipo de transação realizada, o alvo principal do Governo Eletrônico é melhorar o desempenho interno e externo do setor público, focalizando em sua relação com o cidadão.

Chahin et al. (2004, p. 3) comentam que o Brasil desponta como líder em Governo Eletrônico entre os países em desenvolvimento; entretanto, esse movimento desenvolve-se em nível mundial e há várias experiências comprovadamente exequíveis, que com adaptações poderiam ser utilizadas no Brasil com sucesso. Entre os países que dispõem de legislação sobre o assunto, estão a Argentina, Chile, México, Costa Rica, Colômbia e Austrália, além dos países da União Europeia, em função da adoção da Diretiva 115/2001.

Aproveitando este momento de evolução, em termos de gestão, o Governo brasileiro utilizou-se da experiência de Governos Eletrônicos de outros países como modelo, tais como Espanha, Chile e México; e também entrou na era digital com o Sistema Público de Escrituração Digital (SPED), com a finalidade de aproximar o fisco de seus contribuintes (BRASIL, 2009). Este sistema foi instituído pelo Governo brasileiro por meio do Decreto $n .{ }^{\circ} 6.022$, de 22 de janeiro de 2007, e faz parte do Programa de Aceleração do Crescimento (PAC); tem como objetivo a melhoria do controle de processos e apoio ao fisco, além de maior rapidez de acesso às informações dos contribuintes, tendo uma fiscalização mais efetiva das operações, com o cruzamento de dados de auditoria eletrônica.

O SPED pode ser definido como um instrumento que unifica as atividades de recepção, validação, armazenamento e autenticação de livros e documentos integrantes da escrituração comercial e fiscal das empresas, mediante fluxo único e computadorizado de informações. Este sistema irá propiciar benefícios para os contribuintes, tais como: a simplificação das obrigações acessórias; eliminação de digitação de notas fiscais na recepção de mercadorias; redução de erros de escrituração que podem levar ao pagamento de multas; a redução de custos com impressão, aquisição de papel e formulários e armazenamento de documentos, contribuindo para o impacto ambiental favorável (DINIS, 2009).

Com a implantação do SPED, os contribuintes não passarão mais as informações para cada um dos órgãos fiscalizadores em papel e, sim, por meio de um sistema digital on-line. Os arquivos irão para uma base de dados única, e serão compartilhados pelo fisco e demais 
órgãos autorizados. O Governo federal, os estados e as instituições autorizadas poderão acessar diretamente o sistema, obtendo as informações desejadas (BRASIL, 2009b). Nessa linha de pesquisa, considerando o início de implantação do sistema, verifica-se que, no mesmo período de implantação, houve estudos semelhantes sobre o tema no Chile e México (SEPÚLVEDA; VÁSQUEZ; GUTIÉRRES, 2006).

Diante desse contexto, surge a questão que norteará esta pesquisa: qual a percepção dos contribuintes em relação aos impactos da adoção do SPED, nos processos operacionais e redução de custos das empresas que já estiveram envolvidas em, pelo menos, um dos grandes subprojetos do SPED no Estado de São Paulo, e quais as expectativas e percepções desses contribuintes diante do novo sistema? O trabalho tem por objetivo verificar se houve nas referidas empresas melhorias operacionais quando da adoção do SPED. Essas melhorias, tais como a redução de tempo na emissão de NF, diminuição de erros, maior agilidade e produtividade nos processos de recebimento e de transporte de mercadorias, além de diminuição nos gastos com papel e armazenagem de documentos e diminuição das obrigações acessórias são apontadas pelas autoridades governamentais como fatores positivos para as empresas. Os resultados obtidos neste trabalho serão comparados a um estudo semelhante efetuado no Chile.

\section{REFERENCIAL TEÓRICO}

O termo Governo Eletrônico foi usado pela primeira vez, em 1999, nos Estados Unidos da América, pelo então vice-presidente Al Gore; que na época, apontava a possibilidade de os órgãos governamentais se utilizarem tecnologia da informação e comunicação para apoiar e melhorar os serviços públicos à sociedade. De acordo com este fato, pode-se entender que o Governo Eletrônico foi criado para integrar Governo, empresas e cidadãos por meio da tecnologia da informação e comunicação (CHEN et al., 2006).

Na visão de Haldenwang (2004), o Governo Eletrônico é instrumento para aumentar a eficiência da administração pública, melhorar o fornecimento de serviços públicos e reforçar a abertura e a transparência de processos políticos, inclusive licitações. Para Fugini, Maggiolini e Pagamici (2005, p. 306), um dos principais motores de um Governo Eletrônico é a grande expectativa de redução de custos na administração pública que na prática acaba se tornando uma expectativa ilusória, já que os serviços eletrônicos acabam sendo adicionados aos serviços existentes em vez de substituí-los.

Em 2001, o Chile lançou sua estratégia de Governo Eletrônico. Os esforços em torno da implantação deste novo sistema no País têm sido reconhecidos não só nacionalmente, mas também internacionalmente. Há uma série de estudos internacionais que colocam o Chile nos primeiros lugares em relação ao desenvolvimento do Governo Eletrônico em todo o mundo (SEPÚLVEDA; VÁSQUEZ; GUTIÉRRES, 2006, p. 17). O Chile foi um dos primeiros países na América Latina a implantar em seu Governo a validação dos documentos eletrôni- 
cos por meio de um certificado digital. Em março de 2002, promulgou a Lei n. ${ }^{\circ} 19.799$ deste país que trata sobre Documentos Eletrônicos, Assinaturas Eletrônicas e Certificação de Serviços das empresas.

Em busca de aumentar a eficiência de sua prestação de serviços públicos, o México passou a investir na ideia de que a construção de um Governo Eletrônico traz consigo a promessa de contribuir decisivamente para a sua modernização (URRUTIA, 2005, p. 1). Assim como o Chile, o México também foi um dos pioneiros a desenvolver a certificação digital para documentos eletrônicos, em janeiro de 2002, por meio de um decreto. O México teve como objetivo regulamentar a certificação por meio de identificação eletrônica, para ser utilizada em transações eletrônicas. Por meio deste Decreto, o Governo autoriza as empresas devidamente regulamentadas a emitir a certificação digital.

No Brasil, observa-se que o Governo está empenhado em melhorar seus serviços fornecendo por meio da tecnologia da informação e comunicação novos sistemas de relacionamento com o contribuinte (FERRER; SANTOS, 2004). Em todo o mundo, a ideia do Governo Eletrônico é semelhante. Na opinião de Britto (2008, p.1), está sendo iniciada uma nova era regida pela tecnologia da informação, que fará parte do cotidiano dos empresários, de advogados, contadores e demais profissionais: rotinas de transmissão de dados com assinatura digital, manipulação de arquivos eletrônicos, etc. Diante disso, surgiu o SPED.

O SPED consiste na modernização da sistemática atual do cumprimento das obrigações acessórias por parte dos contribuintes, transmitidas às administrações públicas e aos órgãos fiscalizadores. Irá promover um impacto significativo nas empresas, as quais terão que atualizar seus sistemas existentes para atender aos layouts definidos pelo SPED, fazer melhorias em infraestrutura de comunicações para garantir um ambiente adequado ao volume de informações que serão transitadas pela web e revisar sua infraestrutura física para adequação ao novo cenário, como, por exemplo: espaço físico para novos equipamentos de armazenamento de dados eletrônicos (BRASIL, 2009b).

Na visão de Castro (2010), além da redução de custos, os contribuintes não precisarão mais lançar todas as informações contidas nas notas fiscais emitidas e recebidas pela empresa manualmente; esses lançamentos serão feitos eletronicamente, por meio da obtenção dos dados contidos nos arquivos das Notas Fiscais Eletrônicas - NF-e. Esta autora considera que, também haverá diminuição de obrigações acessórias dos contribuintes, a partir da simplificação da forma de lançamento e fornecimento das informações decorrentes destas obrigações aos fiscos; minimizando o tempo despendido para a realização das atividades, além de reduzir o número de erros humanos cometidos no desempenho de tarefas manuais e repetitivas.

Com a implantação do SPED, o cumprimento das obrigações acessórias para com as administrações tributárias e os órgãos fiscalizadores tende a ficar mais moderno; as empresas deixarão de enviar essas obrigações em papel, e passarão a enviar essas informações por meio digital on-line. Elas serão assinadas digitalmente, utilizando-se de um certificado di- 
gital para sua validação. O certificado digital constitui-se em um arquivo eletrônico que serve para a identificação segura da pessoa física ou pessoa jurídica em transações efetuadas via internet. Trata-se de um documento eletrônico de identidade e sua validade jurídica é garantida pela Medida Provisória 2.200-2 de 24 de agosto de 2001.

A Escrituração Contábil Digital (ECD), Escrituração Fiscal Digital (EFD) e a NF-e Ambiente Nacional são os três principais subprojetos que fazem parte do SPED. Baseado na transparência mútua, em busca de reflexos positivos para toda a sociedade, o novo sistema estabelece um novo tipo de relacionamento entre fisco e contribuinte. Além desses três subprojetos, o SPED também é composto por: Nota Fiscal de Serviços Eletrônica (NFS-e); Conhecimento de Transporte Eletrônico (CT-e); Controle Fiscal e Contábil de Transição (FCONT); Livro de Apuração do Lucro Real Eletrônico e Central de Balanços Brasileira (E-Lalur) (em fase inicial de desenvolvimento). Conforme a Receita Federal do Brasil (RFB) (2009), o SPED tem como objetivos:

- promover a integração dos fiscos, mediante a padronização e compartilhamento das informações contábeis e fiscais; respeitadas as restrições legais;

- racionalizar e uniformizar as obrigações acessórias para os contribuintes, com o estabelecimento de transmissão única de distintas obrigações acessórias de diferentes órgãos fiscalizadores; e

- tornar mais célere a identificação de ilícitos tributários, com a melhoria do controle dos processos, a rapidez no acesso às informações e a fiscalização mais efetiva das operações com o cruzamento de dados e auditoria eletrônica.

Dentre os objetivos citados pela Receita federal, chama atenção a preocupação do fisco sobre os ilícitos tributários. Com a implantação do novo sistema, o fisco terá um novo foco: em vez de auditar o passado de uma empresa, o fisco estará mais atento ao presente e poderá projetar o futuro. A NF-e foi o primeiro subprojeto do SPED colocado em prática. Criado em 2005, antes mesmo da criação do próprio sistema, é um documento eletrônico que substitui a nota fiscal em papel, contém dados do contribuinte remetente, do destinatário e da operação a ser realizada (BRANCO, 2009).

Este documento deve ser assinado com certificado digital e enviado à Secretaria da Fazenda (Sefaz) para a sua validação e autorização, ou seja, o contribuinte remetente gera um arquivo no formato padrão da NF-e e, através da internet, envia esse arquivo à Sefaz, que, por sua vez, pode autorizar, ou não, sua emissão definitiva. Somente após a sua autorização, a mercadoria pode circular. (DUARTE, 2008, p.70). Mesmo com os processos digitais, o contribuinte deve imprimir uma via do documento enviado à Sefaz para seguir com a mercadoria. O documento impresso é chamado Documento Auxiliar da Nota Fiscal Eletrônica (Danfe), e cabe ao destinatário verificar a autenticidade do documento fiscal re- 
cebido na Sefaz: a NF-e através da internet ou do próprio Danfe, recebido juntamente com a mercadoria (WALTER; RIBEIRO, 2009).

O sistema da NF-e brasileiro é muito parecido com o sistema de Factura Electrónica criado no Chile em 2002. No Chile, os contribuintes devem solicitar uma autorização para operar com o sistema nomeado de Servicio de Impuestos Internos (SII) (SEPÚLVEDA; VÁSQUEZ; GUTIÉRRES, 2006). Será necessário, também manter o cadastro atualizado das pessoas da empresa autorizadas a operar com o sistema. No Brasil, os contribuintes autorizados a emitir o documento devem adquirir o certificado digital.

Foi desenvolvido no Chile, um dos países pioneiros na implantação de seu Governo Eletrônico em relação à validação digital de documentos, um estudo em período de implantação semelhante ao que está o Brasil. Este estudo chileno foi utilizado como base do instrumento de pesquisa desenvolvido neste trabalho. Na pesquisa chilena, participaram do estudo 500 empresas de diversos portes e segmentos nas regiões metropolitanas de duas regiões: Quinta e Octava, equivalentes a dois estados brasileiros (CHILE, 2009). Foi perguntado aos contribuintes qual seria o principal benefício do novo sistema adotado no país: La Factura Electrónica. Seguem no Gráfico 1 os resultados obtidos no Chile:

\section{Gráfico 1 - Perspectivas em relação aos benefícios de La Factura Electrónica en Chi- le (CHILE, 2009, p. 27).}

\section{PRINCIPALES BENEFICIOS DE LA e-FACTURA}

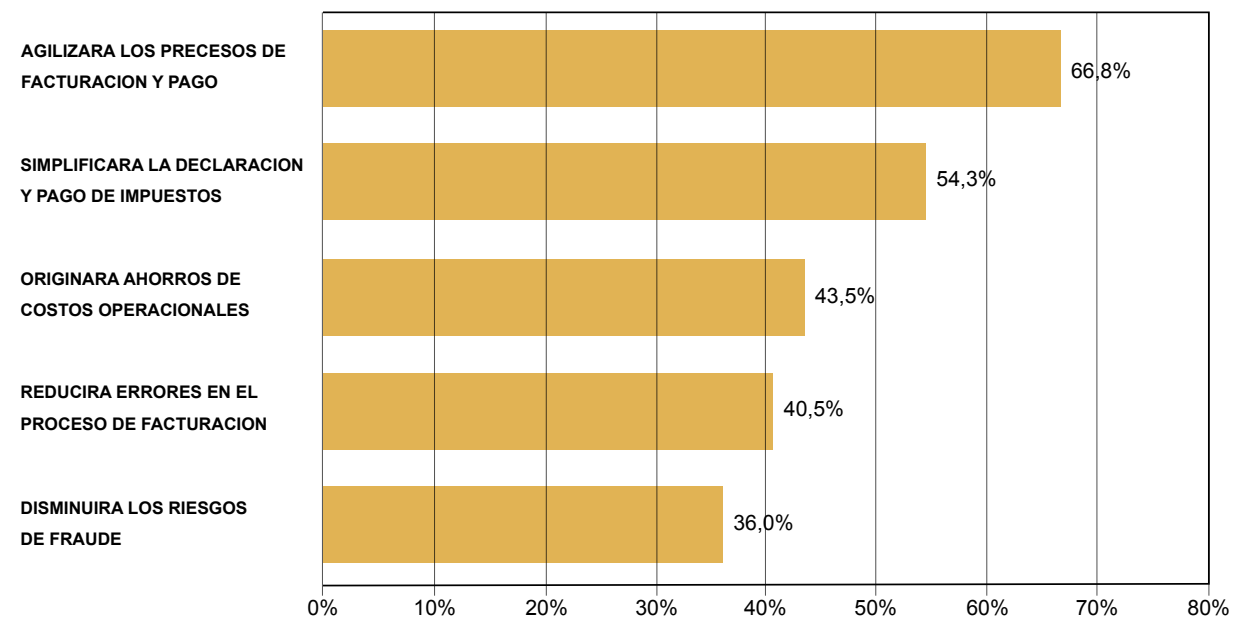

Observa-se que a maioria dos respondentes $(66,8 \%)$ acredita que o sistema da efatura agiliza os processos de faturamento e pagamento, além de simplificar a declaração e pagamento de impostos (54,3\%) e reduzir custos operacionais (43,5\%). Foi destacada, também, a questão da redução dos erros no processo de faturamento (40,5\%), bem como a diminuição dos riscos de fraude (36,0\%). Estes resultados serão comparados ao apurado nesta pesquisa brasileira. 


\section{repec}

SPED - Sistema Público de Escrituração Digital: percepção dos contribuintes em relação os impactos de sua adoção

Além da Nota Fiscal Eletrônica, foi criada em 19 de novembro de 2007, pela Instrução Normativa 787/2007, a Escrituração Contábil Digital, que trata basicamente da substituição dos livros contábeis antes impressos em papel para a versão digital. Os layouts dos arquivos que deverão atender ao SPED são detalhados e definidos pela própria Instrução Normativa citada. De acordo com a Resolução n. ${ }^{0} 1.020$ do Conselho Federal de Contabilidade (CFC), os arquivos apresentados à Receita Federal devem ser de responsabilidade do contabilista, legalmente habilitado com registro no Conselho Regional de Contabilidade (CRC) e as suas validações devem conter as assinaturas digitais do representante legal pela empresa na Receita Federal e do contabilista. Os livros abrangidos são os seguintes: Diário Geral, Diário com Escrituração Resumida (vinculado a livro auxiliar), Diário Auxiliar, Razão Auxiliar e Balancetes Diários e Balanços (CFC, 2009).

A partir do sistema de Contabilidade, a empresa gera um arquivo digital em um formato específico. Este arquivo é submetido ao programa fornecido pelo SPED para validação e assinatura digital e, após esses procedimentos, o arquivo é enviado ao órgão público. Os livros eletrônicos serão registrados na Junta Comercial. Dessa forma, não deverão coexistir livros eletrônicos e em papel de um mesmo período.

Instituída pelo convênio Imposto sobre Circulação de Mercadorias e Serviços (ICMS) n. ${ }^{0}$ 143/2006, em 20/12/2006, a Escrituração Fiscal Digital (EFD) tornou-se um grande subprojeto do SPED. Assegura o compartilhamento de informações relativas às escriturações fiscais e contábeis digitais; em ambiente nacional, com as unidades federadas de localização dos estabelecimentos da empresa, mesmo que estas escriturações sejam centralizadas. Trata-se da substituição de diversas obrigações fiscais entregues ao fisco estadual, que são enviadas por meio eletrônico em diferentes layouts e o ambiente SPED trará uma padronização para elas. Essa escrituração também deve ser validada com a assinatura digital do representante legal da empresa e os seguintes livros são abrangidos: Registro de Entradas, Registro de Saídas, Registro de Inventário, Registro de Apuração do Imposto sobre Produtos Industrializados (IPI) e Registro de Apuração do ICMS.

A NFS-e não é novidade, já que algumas prefeituras adotaram-na. Trata da substituição das Notas Fiscais de Serviços tradicionais por equivalentes na forma digital. A Receita tem como objetivo de incluí-la no cenário SPED, buscar a padronização das informações na tentativa de melhorar a qualidade delas, prestadas aos diferentes órgãos fiscalizadores e aumentar a competitividade entre as empresas do mesmo ramo. A obrigatoriedade da NFS-e compete à legislação municipal. Apesar de cada prefeitura municipal adotar soluções tecnológicas ao seu município, existe um Protocolo de Cooperação n. ${ }^{\circ} 2 / 2007$, a fim de padronizar a NFS-e em todo o Brasil.

Além do SPED Contábil, SPED Fiscal e NF-e, estão em desenvolvimento dois subprojetos: Central de Balanços e o E-Lalur (Livro de Apuração do Lucro Real). A Central de Balanços tem por objetivo a captação de informações contábeis e financeiras, visando obter agregação 
de dados, que serão utilizados para fins de estatísticas, análises nacionais e internacionais, análises de risco, bem como serão disponibilizados à sociedade (MINISTÉRIO DAFAZENDA, 2011a). O E-Lalur tem como objetivo eliminar a redundância das informações existentes na escrituração contábil, no Livro de Apuração do Lucro Real (Lalur) e na Declaração de Imposto de Renda Pessoa Jurídica (DIPJ), e contempla a substituição de uma obrigação conhecida pelos contabilistas pela sua versão digital (MINISTÉRIO DA FAZENDA, 2011b).

Para Duarte (2009), o grande desafio das autoridades fiscais é facilitar a vida de si mesmas e aumentar a "presença fiscal" em um país com mais de 15 milhões de empresas, sendo elas formais e informais. A solução para isso é utilizar-se de tecnologia da informação e conhecimento científico para criar a inteligência fiscal, capaz de realizar operações em larga escala.

Ao longo do tempo, considera-se que o Governo brasileiro pode conseguir ótimos resultados com o SPED. Para isso, basta analisar projetos que tiveram sucesso, como o sistema eleitoral brasileiro e outros avanços tecnológicos, como, por exemplo, a entrega de obrigações acessórias via internet. Em busca de melhorar o cenário atual, a Receita Federal está desenvolvendo outros subprojetos que comporão o SPED. Na sequência, será descrita a metodologia empregada nesta pesquisa.

\section{METODOLOGIA DE PESQUISA}

Este trabalho consiste em um estudo exploratório. Conforme Cooper e Schindler (2003, p. 131), este tipo de estudo é utilizado quando "a área de investigação pode ser tão nova ou tão vaga que o pesquisador precisa fazer uma exploração a fim de saber algo sobre o problema [...]". Para verificar a percepção dos contribuintes em relação os impactos da adoção do SPED, nos processos operacionais e redução de custos das empresas que já estiveram envolvidas em, pelo menos, um dos grandes subprojetos do SPED no Estado de São Paulo e quais as expectativas e opiniões desses contribuintes diante do novo sistema, desenvolveu-se esta pesquisa, semelhante à realizada no Chile, em que alguns resultados foram evidenciados no Gráfico 1.

Além da pesquisa bibliográfica, foi desenvolvida uma Survey. Malhotra (2001, p. 179) comenta que survey é um método de obtenção de informações sobre as percepções dos respondentes. Esta pesquisa tem sua delimitação definida: a) é um recorte no tempo e no espaço, refletindo opiniões de contribuintes no momento de implantação do SPED; b) é um recorte dos contribuintes, pois só reflete a percepção de alguns participantes que já implantaram alguns dos subprojetos, não representando, portanto, a opinião do conjunto de todos os contribuintes obrigados a utilizar os subprojetos do SPED, por força de legislação.

Para a realização da pesquisa, foi utilizado um questionário com 16 (dezesseis) questões em forma de assertivas. Os respondentes foram questionados sobre: o porte das 


\section{repec}

SPED - Sistema Público de Escrituração Digital: percepção dos contribuintes em relação os impactos de sua adoção

empresas dos respondentes; os Subprojetos do SPED que já foram implantados; as perspectivas de implantações dos Subprojetos do SPED; a digitação de dados para emissão da Nota Fiscal Eletrônica; Obrigações Acessórias; impactos causados com a implantação do SPED; redução no tempo de emissão de uma nota fiscal; diminuição de erros nas emissões de notas fiscais com a implantação da Nota Fiscal Eletrônica; agilidade e produtividade no recebimento de mercadorias; redução no tempo das paradas dos caminhões nos postos fiscais; redução na aquisição de papel; quantidades de livros impressos; redução do espaço utilizado para armazenamento de documentos; perspectivas dos contribuintes; diminuição das obrigações acessórias; erros operacionais e principais benefícios do SPED.

O método de amostragem utilizado para esta pesquisa foi o da amostragem intencional, a qual é definida por Cooper e Schindler (2003, p. 169) como "uma amostragem não probabilística que atenda a certos critérios". Os sujeitos foram contatados ao longo de 40 dias, entre final de setembro e início de novembro/2009 por e-mail; mesmo meio utilizado para devolução dos questionários aos pesquisadores. Foram enviados 200 questionários para profissionais da área contábil de empresas de diferentes portes e segmentos na região do Grande ABC.

Foram devolvidos aos pesquisadores 46 questionários, dos quais não foram considerados 7, por se tratarem de indivíduos que não tiveram qualquer contato com pelo menos 1 dos 3 grandes subprojetos do SPED: Nota Fiscal Eletrônica, Escrituração Fiscal Digital e Escrituração Contábil Digital. Os respondentes válidos desta pesquisa são 39 indivíduos que atuam na área contábil e fiscal (23\% Gerentes; $28 \%$ Supervisores e $49 \%$ Analistas), todos trabalhadores em empresas que já estiveram envolvidas com algum subprojeto do SPED na região do Grande ABC.

Quanto à abordagem do problema, esta pesquisa demanda uma abordagem quantitativa, que pressupõe a utilização de instrumentos estatísticos para análise dos dados coletados. Ressalta-se que a abordagem não probabilística de seleção dos casos amostrais impõe restrições quanto à generalização dos resultados obtidos e, por isso, os achados aqui registrados devem ser tomados como referenciais que orientem outros estudos.

Sob essa orientação, o tratamento estatístico empregado aos dados fornece uma descrição da configuração da implantação do SPED nesse grupo amostral, a partir das frequências relativas observadas em cada situação focada. Registra-se que, apesar do moderado número de casos amostrais, sempre que a opção foi pela apresentação dos resultados em percentual, isso se deveu à intenção de facilitar a relativização da situação encontrada.

Dentro desse processo de análise descritiva, foi empregada a análise estatística bivariada, a fim de investigar sobre a presença de associação entre a configuração das unidades empresarias, em termos de implantação do SPED, e a opinião dos entrevistados sobre os impactos gerados por essa implantação em um conjunto de nove itens. Considerando a natureza ordinal da medida das variáveis envolvidas nessa associação, essas 
foram estimadas por meio do uso do Coeficiente V de Cramér e do Coeficiente PHI. Estas medidas funcionam como uma espécie de correlação de variáveis nominais (no mínimo), informando o grau de associação entre as variáveis em uma Tabela 2 × 2 (PHI) ou superior - V de Cramer (LEVIN, 1987; LAY; REIS, 2005).

Com a mesma intenção exploratória de gerar referenciais para novos estudos, esses coeficientes foram submetidos a teste de significância, os quais têm como hipótese nula a não existência de relação entre as variáveis cruzadas. Uma primeira avaliação de associação foi feita entre o número de subprojetos implantados do SPED e a opinião dos entrevistados sobre a ocorrência de impactos na empresa. Uma segunda avaliação envolveu o porte da empresa e a opinião dos entrevistados sobre a ocorrência de impactos. Os resultados obtidos são detalhados no tópico 4.

\section{DESCRIÇÃO E ANÁLISE DOS RESULTADOS}

Neste tópico, serão descritos e analisados os resultados obtidos na pesquisa. Verificou-se a importância de comparar os resultados referentes às expectativas da empresas brasileiras participantes da pesquisa com os resultados do Chile (Gráfico 1). Para analisar o porte das empresas cujos profissionais responderam à pesquisa, perguntou-se qual o faturamento da empresa, de acordo com a Lei n. ${ }^{0} 10.165$, de 27/12/2000. Do total, 59,0\% dos respondentes trabalham em empresas de grande porte; 36,0\% em empresas de médio porte; e 5,0\% em empresas de pequeno porte.

Foram utilizados para tabulação dos dados, os questionários respondidos das empresas que tiveram pelo menos um dos subprojetos do SPED implantados. De um total de 39 empresas respondentes, 33 empresas (84,6\%) implantaram a Nota Fiscal Eletrônica; 30 empresas $(76,9 \%)$ implantaram o SPED Contábil e 22 empresas $(56,4 \%)$ implantaram o SPED Fiscal; 17 empresas, ou seja, 43,6\% das empresas já estão com todos os subprojetos implantados. Complementando a segunda questão, foi constatado que, além dos que já implantaram, 30,8\% pretendem implantar até 2010 e 25,6\% não têm definição de quando serão implantados os referidos subprojetos do SPED. A expectativa é de que, até o final de 2010, grande parte das empresas pesquisadas esteja no cenário SPED.

Constatou-se, também que $41,0 \%$ das empresas que implantaram a Nota Fiscal Eletrônica já tinham tecnologia para importar os dados na emissão de uma nota fiscal; $28,2 \%$ das empresas melhoram seus processos internos com a importação dos dados para a emissão da nota fiscal eletrônica; $25,6 \%$ apenas cumprem a obrigação fiscal, já que continuam digitando os dados para emissão da nota fiscal eletrônica e se utilizam do software gratuito da Sefaz, e 5,1\% não responderam à questão. Percebe-se que poucos contribuintes melhoraram sua operação com a implantação do SPED, sendo que a grande maioria apenas adapta o sistema já existente para comunicação com a Sefaz. 
Considera-se que um dos benefícios do SPED é a redução das obrigações acessórias; porém, não é o que se percebe nesse período inicial. Das 39 empresas que responderam ao questionário, 82,1\% não tiveram qualquer redução em suas obrigações acessórias e 17,9\% deixaram de entregar apenas uma, sendo que a mais comum corresponde à não impressão dos livros contábeis. Dentre os Livros Contábeis obrigatórios, o Livro Diário tem que ser autenticado na Junta Comercial conforme Instrução Normativa 107, do Departamento Nacional do Registro do Comércio (DNRC). Os resultados obtidos neste item evidenciam a insatisfação dos contribuintes em relação às obrigações acessórias, e muitos deles entendem que o SPED soma as obrigações já existentes; ou seja, em vez de diminuir, acabou aumentando o trabalho. Na Tabela 1, a seguir, a percepção dos pesquisados sobre os possíveis impactos operacionais causados pela implantação do SPED foi relacionada com o porte da empresa.

Tabela 1 - Percepção sobre os possíveis impactos operacionais causados pela implantação do SPED a partir do porte das empresas

\begin{tabular}{|c|c|c|c|c|c|}
\hline \multirow{2}{*}{$\begin{array}{l}\text { Porte da } \\
\text { empresa }\end{array}$} & \multirow{2}{*}{$\begin{array}{l}\text { Possíveis } \\
\text { impactos operacionais }\end{array}$} & \multicolumn{4}{|c|}{ Opinião sobre o tamanho do impacto (\% de casos) } \\
\hline & & $\begin{array}{c}0 \% \\
\text { (nenhum impacto) }\end{array}$ & $\begin{array}{c}>0 \% \\
\text { até } 40 \%\end{array}$ & $\begin{array}{c}\text { Censo } \\
2007\end{array}$ & 2006 \\
\hline Pequena e média & \multirow{3}{*}{$\begin{array}{l}\text { Redução no tempo } \\
\text { de emissão de uma } \\
\text { nota fiscal }\end{array}$} & $46,7 \%$ & $40,0 \%$ & $6,7 \%$ & $6,7 \%$ \\
\hline Grande & & $28,6 \%$ & $42,9 \%$ & $19,0 \%$ & $9,5 \%$ \\
\hline Total de casos & & $36,1 \%$ & $41,6 \%$ & $13,9 \%$ & $8,3 \%$ \\
\hline Pequena e média & \multirow{3}{*}{$\begin{array}{l}\text { Diminuição de erros nas emissões de notas } \\
\text { fiscais com a implantação de Nota Fiscal Eletrônica }\end{array}$} & $33,3 \%$ & $40,0 \%$ & $26,7 \%$ & - \\
\hline Grande & & $15,0 \%$ & $50,0 \%$ & $25,0 \%$ & $10,0 \%$ \\
\hline Total de casos & & $22,9 \%$ & $45,7 \%$ & $25,7 \%$ & $5,7 \%$ \\
\hline Pequena e média & \multirow{3}{*}{$\begin{array}{l}\text { Mais agilidade e produtividade no } \\
\text { recebimento de mercadorias }\end{array}$} & $46,7 \%$ & $40,0 \%$ & $13,3 \%$ & - \\
\hline Grande & & $30,0 \%$ & $45,0 \%$ & $20,0 \%$ & $5,0 \%$ \\
\hline Total de casos & & $37,1 \%$ & $42,9 \%$ & $17,1 \%$ & $2,9 \%$ \\
\hline Pequena e média & \multirow{3}{*}{$\begin{array}{l}\text { Redução do tempo das paradas } \\
\text { de caminhões nos postos fiscais }\end{array}$} & $33,3 \%$ & $46,7 \%$ & $20,0 \%$ & - \\
\hline Grande & & $28,6 \%$ & $42,8 \%$ & $23,8 \%$ & $4,8 \%$ \\
\hline Total de casos & & $30,6 \%$ & $44,5 \%$ & $22,2 \%$ & $2,8 \%$ \\
\hline Pequena e média & \multirow{3}{*}{$\begin{array}{l}\text { \% de empresas com percepção de ALTO IMPAC- } \\
\text { TO em todas as operações selecionadas }\end{array}$} & \multicolumn{4}{|c|}{ Nenhum caso } \\
\hline Grande & & \multicolumn{4}{|c|}{ Nenhum caso } \\
\hline Total de casos & & \multicolumn{4}{|c|}{ Nenhum caso* } \\
\hline Pequena e média & \multirow{3}{*}{$\begin{array}{c}\text { \% de empresas com percepção de } \\
\text { NENHUM IMPACTO em todas } \\
\text { as operações }\end{array}$} & \multicolumn{4}{|c|}{$12,5 \%$} \\
\hline Grande & & \multicolumn{4}{|c|}{$8,7 \%$} \\
\hline Total de casos & & \multicolumn{4}{|c|}{$10,3 \%$} \\
\hline & Selecionadas & & & & \\
\hline
\end{tabular}

Fonte: Elaborada pelos autores com base nos dados da pesquisa (2009)

* Apenas 1 (uma) empresa declarou alto impacto em três das quatro operações investigadas.

A nota fiscal de saída, por exemplo, é obrigatória nas transações de vendas, transferências, remessas ou saídas a qualquer título do estabelecimento emissor. A maior agilidade na sua emissão é de extrema importância, a fim de evitar atrasos na saída dos pro- 
dutos do estabelecimento. De acordo com os resultados apurados, dos 39 questionários respondidos verificou-se que a redução não foi significativa; sendo que 13 não sentiram nenhuma melhora nesse sentido; 3 sentiram apenas até 10\% de melhora; 12 perceberam uma melhora relativa de 10 a $40 \%$; apenas 5 sentiram uma melhora razoável de 40 a $70 \%$; 3 empresas consideraram uma melhora significativa de mais de $70 \%$; e os outros 3 que participaram da pesquisa não responderam a essa questão. A grande maioria dos participantes da pesquisa não sentiu redução significativa no tempo de emissão de uma nota fiscal, o que mostra que os contribuintes não tiveram grandes mudanças nesse sentido.

A redução de erros nas emissões de NFs é muito importante para evitar erros no recolhimento de impostos. Pode-se observar que não houve resultado significativo referente à diminuição na quantidade de erros nas emissões de notas fiscais: $68 \%$ das empresas perceberam impacto baixo ou nulo. Apesar de a NF-e ser validada pela Sefaz, os contribuintes que participaram da pesquisa, ainda percebem erros na emissão delas, que podem distorcer as apurações de impostos.

A nota fiscal de saída de um estabelecimento é, consequentemente, a nota fiscal de entrada de outro. Sendo assim, com a implantação da NF-e, é esperado que o receptor da mercadoria tenha mais agilidade no seu recebimento, uma vez que a nota enviada ao Governo seria, ao mesmo tempo, enviada ao receptor. Foi verificado que 13 respondentes não tiveram qualquer agilidade ou melhora de produtividade no recebimento de mercadorias; 8 sentiram apenas até $10 \%$ de melhoras; 7 verificaram uma melhora de 10 a $40 \%$ e, no geral, $71,8 \%$ dos participantes verificaram uma melhora menor que 40\%; 6 observaram maior agilidade de 40 a $70 \%$ e apenas 1 teve resultado de mais de $70 \%$. Verificou-se que 4 participantes não responderam à questão. A porcentagem de agilidade corresponde ao tempo gasto no processo.

Dos resultados apurados, foi verificado que 11 contribuintes não perceberam qualquer tipo de melhoria nos processos, uma vez que os processos de fiscalização permanecem iguais. Se antes os fiscais exigiam a nota fiscal, hoje exigem o Danfe, que acompanha a mercadoria. Outros 11 verificaram uma redução no tempo de até 10\%; 5 participantes verificaram uma redução de 10 a 40\%. Nesses valores, observa-se que 69,2\% dos participantes da pesquisa sentiram uma redução menor que $10 \%$ no tempo das paradas dos caminhões em postos fiscais; ainda, 8 participantes tiveram uma redução de 40 a $70 \%$; e apenas 1 observou uma redução superior a 70\%. Constatou-se que 3 participantes não responderam a esta questão. A Tabela 2, por sua vez, evidencia a percepção dos pesquisados quanto a outros impactos causados pelo SPED: redução de recursos materiais e espaço de armazenagem utilizado. 
Tabela 2 - Opinião sobre os outros impactos indiretos causados pela implantação do SPED a partir do porte das empresas

\begin{tabular}{|c|c|c|c|c|c|}
\hline \multirow{2}{*}{$\begin{array}{l}\text { Porte da } \\
\text { empresa }\end{array}$} & \multirow{2}{*}{$\begin{array}{c}\text { Outros } \\
\text { impactos indiretos }\end{array}$} & \multicolumn{4}{|c|}{ Opinião sobre o tamanho do impacto (\% de casos) } \\
\hline & & $\begin{array}{c}0 \% \\
\text { (nenhum impacto) }\end{array}$ & $\begin{array}{c}>0 \% \text { até } 40 \% \\
\text { (baixo impacto) }\end{array}$ & $\begin{array}{c}>40 \% \text { a } 70 \% \\
\text { (moderado impacto) }\end{array}$ & $\begin{array}{c}>70 \% \\
\text { (alto impacto) }\end{array}$ \\
\hline Pequena e média & \multirow{3}{*}{$\begin{array}{c}\text { Redução na } \\
\text { aquisição de papel } \\
\text { (incluindo formulários) }\end{array}$} & $20,0 \%$ & $60,0 \%$ & $13,3 \%$ & $6,7 \%$ \\
\hline Grande & & $14,3 \%$ & $38,1 \%$ & $14,3 \%$ & $33,3 \%$ \\
\hline Total de casos & & $16,7 \%$ & $47,2 \%$ & $13,9 \%$ & $22,2 \%$ \\
\hline Pequena e média & \multirow{3}{*}{$\begin{array}{l}\text { Diminuição da } \\
\text { quantidade de } \\
\text { livros impressos }\end{array}$} & $33,3 \%$ & $33,3 \%$ & $26,7 \%$ & $6,7 \%$ \\
\hline Grande & & $14,3 \%$ & $28,5 \%$ & $19,0 \%$ & $38,1 \%$ \\
\hline Total de casos & & $22,2 \%$ & $30,5 \%$ & $22,2 \%$ & $25,0 \%$ \\
\hline Pequena e média & \multirow{3}{*}{$\begin{array}{c}\text { Redução do espaço } \\
\text { utilizado para armazena- } \\
\text { mento de documentos }\end{array}$} & $20,0 \%$ & $40,0 \%$ & $33,6 \%$ & $6,7 \%$ \\
\hline Grande & & $9,5 \%$ & $9,5 \%$ & $47,6 \%$ & $33,3 \%$ \\
\hline Total de casos & & $13,9 \%$ & $22,2 \%$ & $41,7 \%$ & $22,2 \%$ \\
\hline Pequena e média & \multirow{3}{*}{$\begin{array}{c}\text { \% de empresas com } \\
\text { percepção de ALTO } \\
\text { IMPACTO em todas as } \\
\text { operações selecionadas }\end{array}$} & \multicolumn{4}{|c|}{-} \\
\hline Grande & & \multicolumn{4}{|c|}{$4,3 \%$} \\
\hline Total de casos & & \multicolumn{4}{|c|}{$2,6 \%$} \\
\hline Pequena e média & \multirow{3}{*}{$\begin{array}{c}\text { \% de empresas com } \\
\text { percepção de NENHUM } \\
\text { IMPACTO em todas as } \\
\text { operações selecionadas }\end{array}$} & \multicolumn{4}{|c|}{$12,5 \%$} \\
\hline Grande & & \multicolumn{4}{|c|}{$4,3 \%$} \\
\hline Total de casos & & \multicolumn{4}{|c|}{$7,7 \%$} \\
\hline
\end{tabular}

Fonte: Elaborada pelos autores com base nos dados da pesquisa (2009)

A redução na aquisição de papéis foi considerada como beneficio do SPED. Verificou-se que, dos 39 participantes da pesquisa, 6 não tiveram qualquer redução de custos na aquisição de papéis; 8 verificaram uma redução de apenas até $10 \%$; 9 sentiram uma redução de 10 a 40\%, ou seja, 59,0\% dos participantes perceberam uma redução de custos menor de 40\%. Dos 16 restantes, 5 tiveram um impacto de 40 a $70 \%, 8$ participantes obtiveram uma redução significativa superior a 70\% e apenas 3 não responderam a questão. A redução de custo com aquisição de papel é um dos benefícios que faz mais sentido, já que o sistema trabalha com arquivos digitais. Porém, não se verificou uma redução de custo significativa nesse início de implantação, resultado que deve ser mudado no futuro.

Tratado como um dos benefícios do SPED, a empresa pode deixar de imprimir os livros contábeis e fiscais e guardá-los apenas de forma digital, já que eles são enviados ao fisco em atendimento à Escrituração Contábil Digital (ECD) e Escrituração Fiscal Digital (EFD). Verificou-se que 8 participantes da pesquisa continuam imprimindo os livros em papel; apenas 3 tiveram uma redução de custos de até 10\%; 8 sentiram uma redução de $10 \%$ a 40\%; outros 8 verificaram uma redução de 40\% a 70\%; 9 tiveram uma redução significativa de mais de 70\%; e 3 participantes não responderam à questão. Enfim, um benefício que vem se concretizando após a implantação do SPED: a substituição dos livros fiscais e 
contábeis em papel pelos seus equivalentes digitais está impactando na redução da quantidade de livros impressos dos contribuintes e beneficiando o meio ambiente.

Diante do cenário SPED, que tem como objetivo trabalhar com os arquivos digitais, as empresas teriam que promover uma alteração em sua infraestrutura física, substituindo os arquivos físicos inativos por arquivos eletrônicos para armazenar seus documentos. Do total, 63,9\% dos pesquisados perceberam impacto de moderado a alto na redução de espaço para armazenamento, o que mostra um resultado satisfatório, já que arquivos digitais não necessitam de grande espaço físico para o seu armazenamento. A Tabela 3, a seguir, mostra a expectativa dos pesquisados quanto a outros benefícios do SPED: diminuição das obrigações acessórias e ausência de erros operacionais.

Tabela 3 - Percepção sobre benefícios gerados pela implantação do SPED a partir do porte das empresas

\begin{tabular}{|c|c|c|c|c|c|}
\hline \multirow{2}{*}{$\begin{array}{l}\text { Porte da } \\
\text { empresa }\end{array}$} & \multirow[b]{2}{*}{ Benefícios } & \multicolumn{4}{|c|}{ Opinião sobre o tamanho do impacto (\% de casos) } \\
\hline & & $\begin{array}{c}0 \% \\
\text { (nenhum impacto) }\end{array}$ & $\begin{array}{c}>0 \% \text { até } 40 \% \\
\text { (baixo impacto) }\end{array}$ & $\begin{array}{c}>40 \% \text { a } 70 \% \\
\text { (moderado impacto) }\end{array}$ & $\begin{array}{c}>70 \% \\
\text { (alto impacto) }\end{array}$ \\
\hline Pequena e média & \multirow{3}{*}{$\begin{array}{c}\text { Diminuição das } \\
\text { obrigações acessórias }\end{array}$} & $31,3 \%$ & $31,3 \%$ & $12,5 \%$ & $25,0 \%$ \\
\hline Grande & & $4,3 \%$ & $34,8 \%$ & $39,1 \%$ & $21,7 \%$ \\
\hline Total de casos & & $15,4 \%$ & $33,3 \%$ & $28,2 \%$ & $23,1 \%$ \\
\hline Pequena e média & \multirow{3}{*}{$\begin{array}{c}\text { Ausência de } \\
\text { erros operacionais }\end{array}$} & $37,5 \%$ & $43,8 \%$ & $18,8 \%$ & - \\
\hline Grande & & $17,4 \%$ & $39,1 \%$ & $30,4 \%$ & $13,0 \%$ \\
\hline Total de casos & & $25,6 \%$ & $41,0 \%$ & $25,6 \%$ & $7,7 \%$ \\
\hline Pequena e média & \multirow{3}{*}{$\begin{array}{l}\text { \% de empresas com } \\
\text { percepção de ALTO } \\
\text { IMPACTO em todos os } \\
\text { itens selecionados }\end{array}$} & \multicolumn{4}{|c|}{-} \\
\hline Grande & & \multicolumn{4}{|c|}{$4,3 \%$} \\
\hline Total de casos & & \multicolumn{4}{|c|}{$2,6 \%$} \\
\hline Pequena e média & \multirow{3}{*}{$\begin{array}{l}\text { \% de empresas com } \\
\text { percepção de NENHUM } \\
\text { IMPACTO em todos os } \\
\text { itens selecionados }\end{array}$} & \multicolumn{4}{|c|}{$31,3 \%$} \\
\hline Grande & & \multicolumn{4}{|c|}{$4,3 \%$} \\
\hline Total de casos & & \multicolumn{4}{|c|}{$15,4 \%$} \\
\hline
\end{tabular}

Fonte: Elaborada pelos autores com base nos dados da pesquisa (2009)

A redução das obrigações acessórias é apontada pelo Governo como um dos benefícios do SPED. No entanto, nesse início de implantação, não se verificou impacto relevante: somente $7,7 \%$ dos pesquisados têm percepção de ter obtido grande diminuição de erros operacionais; e 23,1\% grande diminuição das obrigações acessórias após a implantação do SPED. Alguns comentários foram feitos sobre aumento dessas obrigações nesse período de transição, já que a entrega do ECD e EFD somou-se às anteriores.

Com a implantação do SPED, a expectativa é de que as empresas terão uma redução de erros operacionais, já que a Nota Fiscal Eletrônica só será emitida após uma validação do Sistema on-line do Governo; e o fato de que o fisco terá mais agilidade no acesso às informações dos contribuintes contribuirá para que não errem. Verificou-se 


\section{repec}

SPED - Sistema Público de Escrituração Digital: percepção dos contribuintes em relação os impactos de sua adoção

que 10 dos participantes estão pessimistas e não acreditam que a empresa terá alguma melhora nesse sentido; 8 não pensam que a empresa estará livre de erros, mas acham que haverá uma melhora de até $10 \%$; outros 8 pensam que a empresa terá uma melhora de $10 \%$ a $40 \%$. Diante destes números, verificou-se que $66,7 \%$ dos participantes da pesquisa acreditam que a empresa terá uma melhora em relação a erros operacionais de até $40 \%$; 10 deles pensam que terão uma melhora interessante de $40 \%$ a $70 \%$ e apenas 3 acreditam em uma melhora significativa acima de $70 \%$. Os resultados mostraram que a maior parte ainda não acredita que suas empresas estarão livres de erros operacionais, ou seja, que a implantação do novo sistema contribuirá, ou não, para que a empresa esteja livre de erros operacionais.

A Tabela 4 apresenta os resultados da associação entre o número de projetos implantados do SPED e a opinião dos pesquisados sobre os impactos operacionais - recursos utilizados, redução de obrigações acessórias e de erros operacionais e o número de projetos implantados por empresa. Apresenta, ainda, os resultados obtidos da medida de associação entre as variáveis relacionadas, ou seja, o coeficiente de Cramer (V de Cramer), bem como o nível de significância obtido para essa associação, ajustado para a segunda casa decimal (valor registrado entre parênteses).

O exame da opinião sobre os impactos, segundo o número de projetos implantados do SPED, sugere a presença de associação entre o maior o número de subprojetos implantados nesse sistema e a redução no tempo de emissão de NF, na percepção de maior agilidade e produtividade no recebimento de mercadorias, diminuição das obrigações acessórias e, consequentemente, na diminuição de erros operacionais. Isso significa que o contribuinte que implantou os três subprojetos, tende a apresentar um julgamento mais positivo em relação à obtenção de maiores benefícios que os outros dois grupos.

Embora, isoladamente observe-se associação estatisticamente significante entre a opinião sobre redução do espaço utilizado para armazenamento de documentos e o número de projetos implantados do SPED, essa tendência não é verificada com outros dois itens aparentemente relacionados à redução do espaço para armazenamento, a saber: redução na aquisição de papel e diminuição da quantidade de livros impressos.

Os itens referentes à diminuição de erros nas emissões das NF, redução do tempo das paradas de caminhões nos postos fiscais, além da redução de papel e de livros já comentada, não se mostraram associados ao maior número de subprojetos implantados pela empresa no presente estudo. 
Tabela 4 - Opinião sobre os possíveis impactos operacionais causados pela implantação do SPED a partir do número de subprojetos implantados

\begin{tabular}{|c|c|c|c|c|c|}
\hline \multirow{2}{*}{$\begin{array}{l}\text { Número de } \\
\text { subprojetos } \\
\text { implantados }\end{array}$} & \multirow{2}{*}{$\begin{array}{c}\text { Possíveis impactos } \\
\text { operacionais }\end{array}$} & \multicolumn{4}{|c|}{ Opinião sobre o tamanho do impacto (\% de casos) } \\
\hline & & $\begin{array}{c}\text { Nenhum ou } \\
\text { baixo impacto }\end{array}$ & Moderado a Ito & Coeficiente V de & Decisão1 \\
\hline 1 & \multirow{4}{*}{$\begin{array}{c}\text { Redução no tempo } \\
\text { de emissão de uma } \\
\text { nota fiscal }\end{array}$} & $100,0 \%$ & - & \multirow{4}{*}{$\begin{array}{c}0,440 \\
(\rho=0,03)\end{array}$} & \multirow{4}{*}{$\begin{array}{c}\text { Rejeitar a } \\
\text { hipótese nula }\end{array}$} \\
\hline 2 & & $90,0 \%$ & $10,0 \%$ & & \\
\hline 3 & & $58,8 \%$ & $41,2 \%$ & & \\
\hline Total & & $77,8 \%$ & $22,2 \%$ & & \\
\hline 1 & \multirow{4}{*}{$\begin{array}{l}\text { Diminuição de erros nas } \\
\text { emissões de notas } \\
\text { fiscais com a } \\
\text { implantação de Nota }\end{array}$} & $88,9 \%$ & $11,1 \%$ & \multirow{4}{*}{$\begin{array}{c}0,267 \\
(\rho=0,29)\end{array}$} & \multirow{4}{*}{$\begin{array}{c}\text { Rejeitar a } \\
\text { hipótese nula }\end{array}$} \\
\hline 2 & & $66,7 \%$ & $33,3 \%$ & & \\
\hline 3 & & $58,8 \%$ & $41,2 \%$ & & \\
\hline Total & & $68,6 \%$ & $31,4 \%$ & & \\
\hline 1 & \multirow{4}{*}{$\begin{array}{l}\text { Mais agilidade e } \\
\text { produtividade no } \\
\text { recebimento de } \\
\text { mercadorias }\end{array}$} & $100,0 \%$ & $0,0 \%$ & \multirow{4}{*}{$\begin{array}{c}0,412 \\
(\rho=0,05)\end{array}$} & \multirow{4}{*}{$\begin{array}{c}\text { Rejeitar a } \\
\text { hipótese nula }\end{array}$} \\
\hline 2 & & $90,0 \%$ & $10,0 \%$ & & \\
\hline 3 & & $62,5 \%$ & $37,5 \%$ & & \\
\hline Total & & $80,0 \%$ & $20,0 \%$ & & \\
\hline 1 & \multirow{4}{*}{$\begin{array}{l}\text { Redução do tempo das } \\
\text { paradas de caminhões } \\
\text { nos postos fiscais }\end{array}$} & $77,8 \%$ & $22,2 \%$ & \multirow{4}{*}{$\begin{array}{c}0,247 \\
(\rho=0,33)\end{array}$} & \multirow{4}{*}{$\begin{array}{c}\text { Rejeitar a } \\
\text { hipótese nula }\end{array}$} \\
\hline 2 & & $90,0 \%$ & $10,0 \%$ & & \\
\hline 3 & & $67,7 \%$ & $35,3 \%$ & & \\
\hline Total & & $75,0 \%$ & $25,0 \%$ & & \\
\hline 1 & \multirow{4}{*}{$\begin{array}{l}\text { Redução na aquisição } \\
\text { de papel } \\
\text { (incluindo formulários) }\end{array}$} & $55,6 \%$ & $44,4 \%$ & \multirow{4}{*}{$\begin{array}{c}0,338 \\
(\rho=0,13)\end{array}$} & \multirow{4}{*}{$\begin{array}{c}\text { Rejeitar a } \\
\text { hipótese nula }\end{array}$} \\
\hline 2 & & $90,0 \%$ & $10,0 \%$ & & \\
\hline 3 & & $52,9 \%$ & $47,1 \%$ & & \\
\hline Total & & $63,9 \%$ & $36,1 \%$ & & \\
\hline 1 & \multirow{4}{*}{$\begin{array}{c}\text { Diminuição da } \\
\text { quantidade de livros } \\
\text { impressos }\end{array}$} & $66,7 \%$ & $33,3 \%$ & \multirow{4}{*}{$\begin{array}{c}0,332 \\
(\rho=0,14)\end{array}$} & \multirow{4}{*}{$\begin{array}{c}\text { Rejeitar a } \\
\text { hipótese nula }\end{array}$} \\
\hline 2 & & $70,0 \%$ & $30,0 \%$ & & \\
\hline 3 & & $35,3 \%$ & $64,7 \%$ & & \\
\hline Total & & $52,8 \%$ & $47,2 \%$ & & \\
\hline 1 & \multirow{4}{*}{$\begin{array}{l}\text { Redução do espaço } \\
\text { utilizado para } \\
\text { armazenamento de } \\
\text { documentos }\end{array}$} & $22,2 \%$ & $77,8 \%$ & \multirow{4}{*}{$\begin{array}{c}0,438 \\
(\rho=0,03)\end{array}$} & \multirow{4}{*}{$\begin{array}{c}\text { Rejeitar a } \\
\text { hipótese nula }\end{array}$} \\
\hline 2 & & $70,0 \%$ & $30,0 \%$ & & \\
\hline 3 & & $23,5 \%$ & $76,5 \%$ & & \\
\hline Total & & $36,1 \%$ & $63,9 \%$ & & \\
\hline 1 & \multirow{4}{*}{$\begin{array}{c}\text { Diminuição das } \\
\text { obrigações acessórias }\end{array}$} & $81,8 \%$ & $18,2 \%$ & \multirow{4}{*}{$\begin{array}{c}0,697 \\
(\rho<0,01)\end{array}$} & \multirow{4}{*}{$\begin{array}{c}\text { Rejeitar a } \\
\text { hipótese nula }\end{array}$} \\
\hline 2 & & $80,0 \%$ & $20,0 \%$ & & \\
\hline 3 & & $11,1 \%$ & $88,9 \%$ & & \\
\hline Total & & $48,7 \%$ & $51,3 \%$ & & \\
\hline 1 & & $81,8 \%$ & $18,2 \%$ & & \\
\hline 2 & Ausência de erros & $100,0 \%$ & $0,0 \%$ & 0,564 & Rejeitar a \\
\hline 3 & operacionais & $38,9 \%$ & $61,1 \%$ & $(\rho<0,01)$ & hipótese nula \\
\hline Total & & $66,7 \%$ & $33,3 \%$ & & \\
\hline
\end{tabular}

Fonte: Elaborada pelos autores com base nos dados da pesquisa (2009)

1 Hipótese nula: Não há associação entre o número de projetos implantados na empresa e a avaliação do impacto operacional “i”. 
A Tabela 5 apresenta os resultados da associação das variáveis referentes à opinião dos pesquisados sobre os impactos operacionais e o número de projetos implantados do SPED. Também, apresenta os resultados obtidos da medida de associação entre as variáveis investigadas, nesse caso o coeficiente de PHI, bem como do nível de significância obtido, ajustado para a segunda casa decimal, registrado entre parênteses.

Tabela 5 - Opinião sobre os possíveis impactos operacionais causados pela implantação do SPED a partir do porte das empresas.

\begin{tabular}{|c|c|c|c|c|c|}
\hline \multirow[b]{2}{*}{$\begin{array}{l}\text { Porte da } \\
\text { empresa }\end{array}$} & \multirow[b]{2}{*}{$\begin{array}{c}\text { Possíveis impactos } \\
\text { operacionais }\end{array}$} & \multicolumn{4}{|c|}{ Opinião sobre o tamanho do impacto (\% de casos) } \\
\hline & & $\begin{array}{c}\text { Nenhum ou } \\
\text { baixo Impacto } \\
\text { (0 a 40\%) }\end{array}$ & $\begin{array}{l}\text { Moderado a } \\
\text { alto impacto } \\
\quad(>40 \%)\end{array}$ & $\begin{array}{l}\text { Coeficiente de } \\
\text { associação PHI }\end{array}$ & Decisão ${ }^{1}$ \\
\hline Pequena e média & \multirow{3}{*}{$\begin{array}{l}\text { Redução no tempo de } \\
\text { emissão de uma } \\
\text { nota fiscal }\end{array}$} & $86,7 \%$ & $13,3 \%$ & \multirow{3}{*}{$\begin{array}{c}0,181 \\
(\rho=0,28)\end{array}$} & \multirow{3}{*}{$\begin{array}{c}\text { Aceitar a } \\
\text { hipótese nula }\end{array}$} \\
\hline Grande & & $71,4 \%$ & $28,6 \%$ & & \\
\hline Total de casos & & $77,8 \%$ & $22,2 \%$ & & \\
\hline Pequena e média & \multirow{3}{*}{$\begin{array}{c}\text { Diminuição de erros nas } \\
\text { emissões de notas fiscais } \\
\text { com a implantação de Nota } \\
\text { Fiscal Eletrônica }\end{array}$} & $73,3 \%$ & $26,7 \%$ & \multirow{3}{*}{$\begin{array}{c}0,089 \\
(\rho=0,59)\end{array}$} & \multirow{3}{*}{$\begin{array}{c}\text { Aceitar a } \\
\text { hipótese nula }\end{array}$} \\
\hline Grande & & $65,0 \%$ & $35,0 \%$ & & \\
\hline Total de casos & & $68,6 \%$ & $31,4 \%$ & & \\
\hline Pequena e média & \multirow{3}{*}{$\begin{array}{c}\text { Mais agilidade e } \\
\text { produtividade no } \\
\text { recebimento de mercadorias }\end{array}$} & $86,7 \%$ & $13,3 \%$ & \multirow{3}{*}{$\begin{array}{c}0,144 \\
(\rho=0,39)\end{array}$} & \multirow{3}{*}{$\begin{array}{c}\text { Aceitar a } \\
\text { hipótese nula }\end{array}$} \\
\hline Grande & & $75,0 \%$ & $25,0 \%$ & & \\
\hline Total de casos & & $80,0 \%$ & $20,0 \%$ & & \\
\hline Pequena e média & \multirow{3}{*}{$\begin{array}{c}\text { Redução do tempo das } \\
\text { paradas de caminhões nos } \\
\text { postos fiscais }\end{array}$} & $80,0 \%$ & $20,0 \%$ & \multirow{3}{*}{$\begin{array}{c}0,098 \\
(\rho=0,56)\end{array}$} & \multirow{3}{*}{$\begin{array}{c}\text { Aceitar a } \\
\text { hipótese nula }\end{array}$} \\
\hline Grande & & $71,4 \%$ & $28,6 \%$ & & \\
\hline Total de casos & & $75,0 \%$ & $25,0 \%$ & & \\
\hline Pequena e média & \multirow{3}{*}{$\begin{array}{c}\text { Redução na aquisição de } \\
\text { papel (incluindo formulários) }\end{array}$} & $80,0 \%$ & $20,0 \%$ & \multirow{3}{*}{$\begin{array}{c}0,283 \\
(\rho=0,09)\end{array}$} & \multirow{3}{*}{$\begin{array}{c}\text { Aceitar a } \\
\text { hipótese nula }\end{array}$} \\
\hline Grande & & $52,4 \%$ & $47,6 \%$ & & \\
\hline Total de casos & & $63,9 \%$ & $36,1 \%$ & & \\
\hline Pequena e média & \multirow{3}{*}{$\begin{array}{l}\text { Diminuição da quantidade } \\
\text { de livros impressos }\end{array}$} & $66,7 \%$ & $33,3 \%$ & \multirow{3}{*}{$\begin{array}{c}0,235 \\
(\rho=0,16)\end{array}$} & \multirow{3}{*}{$\begin{array}{c}\text { Aceitar a } \\
\text { hipótese nula }\end{array}$} \\
\hline Grande & & $42,9 \%$ & $57,1 \%$ & & \\
\hline Total de casos & & $52,8 \%$ & $47,2 \%$ & & \\
\hline Pequena e média & \multirow{3}{*}{$\begin{array}{c}\text { Redução do espaço utilizado } \\
\text { para armazenamento de } \\
\text { documentos }\end{array}$} & $60,0 \%$ & $40,0 \%$ & \multirow{3}{*}{$\begin{array}{c}0,420 \\
(\rho=0,01)\end{array}$} & \multirow{3}{*}{$\begin{array}{c}\text { Rejeitar a } \\
\text { hipótese nula }\end{array}$} \\
\hline Grande & & $19,0 \%$ & $81,01 \%$ & & \\
\hline Total de casos & & $36,1 \%$ & $63,9 \%$ & & \\
\hline Pequena e média & \multirow{3}{*}{$\begin{array}{c}\text { Diminuição das obrigações } \\
\text { acessórias }\end{array}$} & $62,5 \%$ & $37,5 \%$ & \multirow{3}{*}{$\begin{array}{c}0,230 \\
(\rho=0,15)\end{array}$} & \multirow{3}{*}{$\begin{array}{c}\text { Aceitar a } \\
\text { hipótese nula }\end{array}$} \\
\hline Grande & & $39,1 \%$ & $60,09 \%$ & & \\
\hline Total de casos & & $48,7 \%$ & $51,3 \%$ & & \\
\hline Pequena e média & \multirow{3}{*}{$\begin{array}{l}\text { Ausência de erros } \\
\text { operacionais }\end{array}$} & $81,3 \%$ & $18,8 \%$ & \multirow{3}{*}{$\begin{array}{c}0,258 \\
(\rho=0,11\end{array}$} & \multirow{3}{*}{$\begin{array}{c}\text { Aceitar a } \\
\text { hipótese nula }\end{array}$} \\
\hline Grande & & $56,5 \%$ & $43,5 \%$ & & \\
\hline Total de casos & & $66,7 \%$ & $33,3 \%$ & & \\
\hline
\end{tabular}

Fonte: Elaborada pelos autores com base nos dados da pesquisa (2009) 
De forma geral, não existe relação entre o porte da empresa e a opinião dos pesquisados em relação aos possíveis impactos operacionais apresentados após a implantação de algum dos subprojetos do SPED. A exceção é a redução do espaço utilizado para armazenamento de documentos, ou seja, percebe-se esse impacto positivo principalmente nas grandes empresas.

Muitos dos participantes ficaram divididos e escolheram mais de uma opção na questão relacionada aos benefícios obtidos pelo SPED. Dos 39 respondentes, 56,4\% perceberam que um dos principais benefícios do SPED será a diminuição no risco de fraudes; o segundo benefício mais apontado foi a redução e a simplificação no cumprimento das obrigações acessórias, com 41,0\%, seguido da diminuição de custos operacionais (aquisição, impressão e armazenamento de papéis), com 30,8\% dos participantes; a agilidade nos processos de faturamento e pagamento teve $25,6 \%$ de escolha; e apenas $15,4 \%$ dos participantes acreditam que um dos principais benefícios do SPED será a redução de erros nas emissões de notas fiscais.

\section{Gráfico 1 - Perspectivas em relação aos benefícios do SPED}

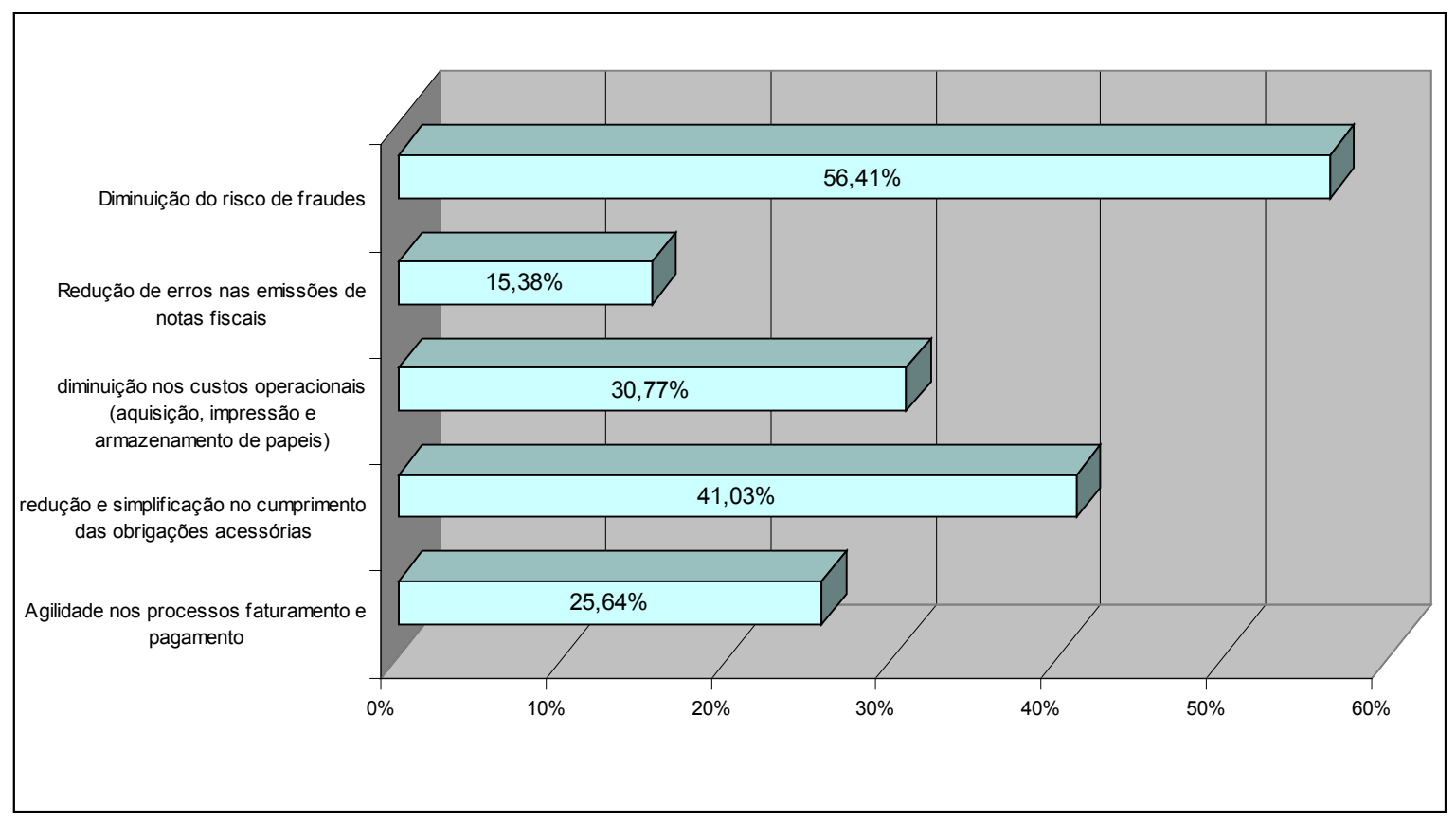

Fonte: Elaborado pelos autores com base nos dados da pesquisa (2009)

Curiosamente, ainda que em nível exploratório, observa-se que o resultado mais escolhido no Brasil: Diminuição de Riscos de Fraudes com 56,4\% foi o resultado menos escolhido no Chile com 36,0\%. No Chile (Gráfico 1), o mais escolhido como um dos principais benefícios do sistema foi a agilidade nos processos de faturamento e pagamento; no Brasil o mesmo benefício ficou com $25,6 \%$ e foi a quarta opção mais escolhida. Outro fato interessante corresponde à redução e à simplificação das obrigações acessórias. No Chile, 
o benefício correspondente a este no Brasil foi o segundo mais escolhido, com $54,3 \%$. No Brasil, verificou-se que este benefício também foi o segundo mais escolhido, com $41,0 \%$. Outro benefício que, coincidentemente, foi o terceiro mais escolhido nos dois países foi a redução de custos operacionais, com $43,5 \%$ no Chile e $30,8 \%$ no Brasil. A redução de erros nas emissões de notas fiscais também pode ser comparada: no Chile, este benefício foi o quarto mais escolhido, com 40,5\%; já no Brasil, foi o quinto e menos escolhido pelos participantes, com apenas $15,4 \%$.

\section{CONSIDERAÇÕES FINAIS}

Na pesquisa bibliográfica, constatou-se que, no Brasil, há poucas análises sobre o tema, sendo que a maioria dos estudos existentes visa mensurar os impactos favoráveis ao Governo, como, por exemplo, o maior controle nas fiscalizações e combate à sonegação de impostos.

O Sistema Público de Escrituração Digital (SPED) constitui-se em uma revolução, caracterizada pela transição da Contabilidade em papel para a Digital; gerando significativa redução nos custos; aumentando a celeridade do processo; auxiliando no combate à sonegação, além de possibilitar o cruzamento de informações entre contribuintes, entre outras vantagens.

A verificação de alguma ocorrência de sonegação fiscal e demais irregularidades quanto ao cumprimento das obrigações tributárias e fiscais será facilitada às administrações fazendárias, de maneira que o cruzamento de informações ocorrerá por meio eletrônico e por um sistema criado para essa finalidade, e não mais de forma manual, como ainda acontece em grande parte dos casos nos dias atuais.

O objetivo da pesquisa foi atingido e os resultados obtidos na pesquisa apresentaram o fato de que o início de implantação do sistema ainda não proporcionou benefícios significativos aos participantes da pesquisa. Verificou-se que os contribuintes não obtiveram resultados satisfatórios em termos de redução no tempo de emissão de uma nota fiscal, maior agilidade e produtividade no recebimento de mercadorias e redução na aquisição de papel (incluindo formulários).

Pode-se observar que os contribuintes que participaram da pesquisa obtiveram redução de custo razoável com a implantação do SPED, principalmente em relação ao espaço utilizado para armazenamento de documentos. Por outro lado, alguns profissionais alertaram sobre o investimento necessário da implantação do novo sistema, inclusive para substituir o armazenamento de documentos físicos pelo armazenamento de documentos digitais.

Embora os benefícios apontados pelo Governo não tenham sido percebidos como significativos no início de implantação, verificou-se que os contribuintes estão divididos em suas perspectivas quanto ao novo sistema. Cerca de $51,3 \%$ dos contribuintes brasileiros 
pesquisados acreditam em uma melhora significativa na redução do número de obrigações acessórias, e muitos têm a perspectiva de que terão benefícios no futuro, principalmente em relação à diminuição dos riscos de fraudes e à diminuição dos custos operacionais.

Para estudos futuros, sugere-se investigar a hipótese de que o contribuinte que implanta os três subprojetos SPED percebe um maior impacto positivo em relação aos aspectos operacionais (eficiência, produtividade, diminuição de erros) e materiais (gastos com papel e custo de arquivo).

\section{REFERÊNCIAS}

BRANCO, L. O. de A. Nota Fiscal Eletrônica e SPED: aspectos práticos e implicações tributárias. 2008. Jus Navegandi. Disponível em: <http://jus2uol.com.br/doutrina/texto. asp?id-10920>. Acesso em: 20 ago. 2009.

BRASIL. O Gov.br - Governo Eletrônico. Disponível em: <http://www.governoeletronico. gov.br/o-gov.br>. Acesso em 26 nov. 2009a.

BRASIL. Nota fiscal eletrônica. Disponível em <http://www.nfedobrasil.com.br/pdf/CARTILHA\%20SPED\%20BRASIL.pdf>. acesso em 10 set. 2009>. Acesso em 10 set. 2009b.

BRITTO, D. SPED - Sistema Público de Escrituração Digital. 2008. Jus Vigilantibus. Disponível em <http://jusvi.com/artigos/35924>. Acesso em 21 set. 2009.

CASTRO, M. G. SPED - Sistema Público de Escrituração Digital. SPED - Digital Bookkeeping System. Disponível em: <http://www.conpedi.org/manaus/arquivos/anais/brasilia/10_86.pdf> Acessado em: 22 Fev 2010.

CFC - Conselho Federal de Contabilidade. Resolução 1.020. Disponível em: <http:://cfc. org.br> Acesso em: 19 Fev 2010.

CHAHIN, A. et al. E-gov.br: a próxima revolução brasileira. São Paulo: Prentice Hall, 2004.

CHEN, Y. N.; CHEN, H. M.; HUANG, W.; CHING, R. K. H. E-Government Strategies in Developed and Developing Countries: An Implementation Framework and Case Study. Journal of Global Information Management. V. 14, n. ${ }^{0}$ 1, 23-46, January-March 2006.

CHILE. Perspectivas de La Factura Electrónica en Chile. 2003. Centro de Estúdios de la Economia Digital. Disponível em <http://www.stanmetalcomputacion.cl/estudioFacturaElectronica.pdf>. Acesso em 13 out. 2009. 
COOPER, D. R.; SCHINDLER, P. S. Métodos de Pesquisa em Administração. 7a. Ed. Porto Alegre: Bookman, 2003.

DINIS, E. H. O governo eletrônico no Brasil: Perspectiva histórica a partir de um modelo estruturado de análise. Revista de Administração Pública. V.43, Fev. 2009.

DUARTE, R. D. Big Brother Fiscal na era do conhecimento. 2a. Ed. Minas Gerais: Ideas@work, 2008.

FERRER, F.; SANTOS, P. (org.). E-goverment: O governo eletrônico no Brasil. São Paulo: Saraiva, 2004.

FUGINI, M.G.; MAGGIOLINI , P.; PAGAMICI, B. Por que é difícil fazer o verdadeiro "Governo Eletrônico"? Revista Produção, v. 15, n. 03. 2005.

HALDENWANG, C. Electronic Government (E-Government) and Development Does the Digital Divide Contribute to the Governance Divide? Proceedings... IN: EADI-conference in Ljubljana. 2004.

HELBIG, N. C.; GIL-GARCÍA, J. R.; FERRO, E. Understanding the Complexity in Electronic Government: Implications from the Digital Divide literature. Proceedings... IN: Eleventh Americas Conference on Information Systems, Omaha, NE, USA August 11th-14th 2005.

LAY, M.C.D.; REIS, A.T.L. Análise quantitativa na área de estudos ambiente-comportamento. Ambiente Construído. V. 5, No. 2, p. 21-36, abr./jun. 2005.

LEVIN, Jack. Estatística aplicada a ciências humanas. 2a. Ed. São Paulo, Harbra, 1987.

MALHOTRA, N. K. Pesquisa de marketing: uma orientação aplicada. 3a. Ed. Porto Alegre: Bookman, 2001.

MINISTÉRIO DA FAZENDA. Central de Balanços. Disponível em: <http://www1.receita. fazenda.gov.br/outros-projetos/central-de-balancos.htm> Acesso em 02 Abr 2011a.

MINISTÉRIO DA FAZENDA. E-LALUR. Disponível em: <http://www1.receita.fazenda.gov. br/outros-projetos/e-lalur.htm> Acesso em 02 Abr 2011b. 
RFB. Receita Federal do Brasil. SPED. Disponível em <http://www1.receita.fazenda.gov.br/ sobre-o-projeto/apresentacao.htm>. Acesso em 10 set. 2009.

SCHEDLER, K.; SCHARF, M. C. Exploring The Interrelations Between Electronic Government And The New Public Management. A Managerial Framework For Electronic government. Proceedings... In: Conference Zurich, October 2001. Disponível em citeseerx.ist.psu.edu/viewdoc/download;jsessionid.

SEPÚLVEDA, M.A.T.; VÁSQUEZ, A.V.; GUTIÉRRES, P.G. Gobierno Electronico em Chile 2000-2005. Chile: Maval. 2006.

SIQUEIRA, M.L. A Economia da Sonegação - Teorias e Evidências Empíricas. Revista Economia Contemporânea. 2005.

URRUTIA, E.R. La Expectativa Mexicana en la construcción de la estratégia gobierno electrónico. Programa de investigación em Telecomunicaciones Del CIDE, 2005.

WALTER, J.P; RIBEIRO, O.D.J. Sistema Público de Escrituração Digital e Nota Fiscal Eletrônica: O Brasil evoluindo com o contribuinte. Revista Eletrônica de Contabilidade da Universidade Federal de Santa Maria, n. 02. Disponível em <http://w3.ufsm.br/revistacontabeis/anterior/artigos/vIVn02/t008.pdf>. Acesso em 21 set. 2009. 